\title{
Association between Self-esteem and Smoking among Religious Schools Students in Petaling District, Selangor
}

Jinadu LO, Salmiah MS, Azuhairi AA

Department of Community Health, University Putra Malaysia, Selangor, Malaysia

\begin{abstract}
Introduction : According to the Youth Behaviour Risk Factor Surveillance (YBRFSS, 2011) in Malaysia, the prevalence of smokers nationally among Form 1, 2 and 4 students government secondary school students was $9.1 \%$ (ever smokers) and $8.7 \%$ (current smokers). However, there is limited information on the prevalence of smoking among religious secondary school students and self-esteem as risk factor. Thus, this study was conducted to determine the prevalence and factors associated with smoking among the religious secondary school students in Petaling district, Selangor. Methods: A cross-sectional study was conducted among 899 students. The schools were selected using cluster sampling and self-administered questionnaire was used. Data was analyzed using chi-square test and multivariate logistic regression to identify the independent factors for smoking. Results: The response rate was $94 \%$. The prevalence of ever smoking was $10.1 \% ; 3.9 \%$ among female and $18.6 \%$ among male. The median age (interquartile range) of smoking initiation was $12.00(4.01)$ years. The results showed that independent factors for smoking were: males (OR= 5.47); age group 14-15years ( $O R=2.82)$ and $16-17$ years $(O R=3.63)$ and having low self -esteem $(O R=6.24)$. Conclusion: prevalence of ever smokers is higher when compared to YBRFSS, (2011) and it was revealed that most of the smokers started smoking even before secondary school. The results also revealed the importance of promoting self-esteem. Efforts in smoking prevention should therefore be focused on curbing the initiation of the acts and improving students' self-worth.
\end{abstract}

KEYWORDS: Smoking, socio-demographic characteristics, self-esteem

\section{INTRODUCTION}

Smoking is one of the most important public health problems worldwide. Studies estimated that in developed countries as a whole, tobacco was responsible for $24 \%$ of all male deaths and $7 \%$ of all female deaths. ${ }^{1}$ According to WHO estimates, approximately $47 \%$ of men and $12 \%$ of women smoke cigarettes worldwide in $2010 .^{2}$ The report also indicated that the death of 5 million individuals worldwide every year is due to smoking-related diseases. ${ }^{2}$ Crofton and Simpson $(2002)^{3}$ reported that by 2030 , tobacco is expected to be the single biggest cause of death worldwide causing more deaths than Human Immunodeficiency Virus (HIV), tuberculosis, malaria, maternal mortality, automobile crashes, homicides and suicides combined. ${ }^{3}$ No other consumer product has even come close to inflicting this degree of harm to the world population.

Corresponding author:

Salmiah binti Md Said

Medical Lecturer

Department of Community Health,

Universiti Putra Malaysia,

Selangor, Malaysia.

Hp: +60136362574

E-mail:salmiahms@upm.edu.my
Cigarette smoking has been described as a "gateway" substance towards illicit drug use among adolescents ${ }^{4}$ and the fact that many adult smokers initiated their smoking habit as adolescents makes adolescence smoking a significant public health problem. ${ }^{4}$ The tobacco industry in Malaysia is a flourishing one. The industry is estimated to worth more than 2 billion United States Dollars (USD 2 billion) with three major companies actively dominating the industry. ${ }^{5}$ Besides the legal tobacco trade in Malaysia, illicit cigarette trade such as sales to minors and teens has grown accounting for about one fifth of the tobacco market in the country. ${ }^{5}$

Previous studies have showed that most smokers start to smoke in their early teenage years or even before becoming teenagers. Pierce and Gilpin, $1996^{6}$ revealed that $50 \%$ of adolescents who start to smoke go on smoking for at least 16 to 20 years indicating that control and preventive measures should be focussed at preventing the initiation of the act. ${ }^{6}$

Smoking among adolescents have been associated with socio-demographic factors [(ethnicity (Malay in Malaysia), higher age, male gender)]; environmental factors (exposure to cigarette advertisement in Magazines, TV, billboards), family factors (parental 
smoking, staying with parents or their negative attitude to smoking); behavioural factors (risktaking behaviours such as physical fighting, alcohol use, drug use, sexual activity) (Rashid \& Azizah, 2011; ${ }^{7}$ Lee et al., 2005) ${ }^{8}$ but most of these studies were conducted in government schools and a nonreligious settings. 7,8

Previous studies have alsindicated that smoking students had lower mental health status (selfesteem inclusive) in comparison with nonsmoking students (McGee \& Williams, 2006) ${ }^{9}$ while Byrne and Mazanov $(2001)^{10}$ specifically reported a significant association between self-esteem and smoking indicating that low self-esteem significantly predicts smoking . 9,10

Therefore, the aim of this study is to describe the prevalence of smoking and its association with socio-demographic factors and self-esteem among religious secondary schools students in Petaling district, Selangor.

\section{MATERIALS \& METHODS}

A cross-sectional study was conducted among 899 students from three schools out of the four religious schools in the district. The estimated sample size was 866 and was calculated based on two proportion formula for hypothesis testing. The schools were selected using cluster sampling and all students in the selected schools who fulfilled the inclusion criteria were recruited for the study.

The inclusion criteria for the respondents that were included in this study are students in form 1, 2, 4 and also students who have a history of living with family and (or) parent. Students who are nonMalaysians were excluded from the study. The sampling frame used was the list of religious schools in the district that registered under Jabatan Agama Islam Negeri Selangor.

The study instrument used for the study is a selfadministered questionnaire containing ten items. Self-esteem was measured using a validated selfesteem scale. The questions were adapted from Rosenberg, (1965). ${ }^{11}$ The validated Malay version of the self-esteem scale was used in the study Mohd. Jamil, (2006). ${ }^{12}$ Questions probing student's self-esteem, their attitude toward themselves were asked and their level of satisfaction towards themselves was asked in the questionnaire.

The dependent variable in the study is smoking. Smoking in the study was defined as 'adolescents who have ever tried smoking, even one puff'. The independent variables studied were socio- demographic factors and self-esteem. Self-esteem was categorized into low (score < 15), normal (score 15-25) and high self- esteem (score $>25$ ).

Data was analyzed using chi-square test for association between two categorical variables and logistic regression to identify the independent factor for smoking. Logistic regression was used to determine the factors associated with smoking. The odds ratio and $95 \%$ confidence interval $(\mathrm{CI})$ was used to define the strength of association between individual independent variable and smoking.

Binary logistic regression using the 'Enter method' was performed on the variables that were found to be significant in bivariate analysis and those that had $P$ value less than 0.25 (Hosmer, Lemeshow \& Sturdivant, 2013) to control for confounders and examine the association of independent predictors on the ever smokers.

\section{RESULTS}

\section{General Characteristics of the Respondents}

Table I shows the characteristics of respondents by their socio-demography. Among the 899 respondents in this study 518 (57.6\%) were females and 381 (42.4\%) were males. The age of the respondents ranged from 12 to 17 years old. The median \pm (IQR) age of the respondents is $14 \pm(1.00)$ years. Among the respondents involved in the survey 355 (39.5\%) are in Form 1, 335 (37.3\%) are in Form 2 and 209 (23.2\%) are in Form 4.

For ethnicity, most of the respondents were Malay 893 (99.3\%) while Chinese and Indians were both 3 $(0.3 \%)$ each. The median age of the respondents is 14.00 years. More than half of the respondents [462 sstudents (51.4\%)] attended a government primary school, 26 (2.9\%) respondents attended private primary school, 285 of them (31.7\%) attended government religious primary school and 113 (12.6\%) of the respondents attended private religious primary school.

\section{Characteristics of Respondents by Self-esteem}

Table I also shows the distribution of respondents by their self-esteem status which ranges from 7 to 30 . The median (IQR) self-esteem of respondents was $19.00 \pm(5.00)$. The result also indicated that most of the respondents have normal self-esteem with only $10.5 \%$ of the respondents having low selfesteem and $6.8 \%$ have a high self-esteem. 
Table I: Distribution of the respondents by socio-demographic characteristics and self esteem

\begin{tabular}{|c|c|c|c|}
\hline Socio-demographic factors & $\begin{array}{l}\text { Frequency } \\
\mathrm{N}=899\end{array}$ & Percentage & Median(IQR) \\
\hline \multicolumn{4}{|l|}{ Gender } \\
\hline Male & 381 & 42.4 & \\
\hline Female & 518 & 57.6 & \\
\hline Age (Years) & & & $14.00(1.00)$ \\
\hline $12-13$ years & 356 & 39.6 & \\
\hline $14-15$ years & 334 & 37.2 & \\
\hline 16-17years & 209 & 23.2 & \\
\hline \multicolumn{4}{|l|}{ Ethnicity } \\
\hline Malay & 893 & 99.3 & \\
\hline Chinese & 3 & 0.3 & \\
\hline India & 3 & 0.3 & \\
\hline \multicolumn{4}{|l|}{ Class } \\
\hline Form 1 & 355 & 39.5 & \\
\hline Form 2 & 335 & 37.3 & \\
\hline Form 4 & 209 & 23.2 & \\
\hline \multicolumn{4}{|l|}{ Primary Education } \\
\hline Government School & 462 & 51.4 & \\
\hline Private School & 26 & 2.9 & \\
\hline State Religious & 285 & 31.7 & \\
\hline Private Religious & 113 & 12.6 & \\
\hline International & 3 & 0.3 & \\
\hline Others & 10 & 1.1 & \\
\hline Level of self esteem & & & $19.00(5.00)$ \\
\hline Low $(<15)$ & 94 & 10.5 & \\
\hline Normal (15-25) & 744 & 82.8 & \\
\hline High $(>25)$ & 61 & 6.8 & \\
\hline
\end{tabular}

\section{Characteristics of Respondents by Smoking Status}

Table II shows the distribution of respondents by their smoking characteristics. The prevalence of ever smoking among the students was found to be 91 $(10.1 \%) 95 \% \mathrm{Cl}(8.1,12.0)$. The proportion of eversmokers among females was $3.9 \%$ and $18.6 \%$ among the male respondents. The median (IQR) age of smoking initiation was $12.00(4.00)$ years.

Most of the ever smokers $(36.3 \%)$ reported to have first tried smoking between 10-12 years old followed by $28(30.7 \%)$ who indicated that they first tried smoking at $13-15$ years old. About $24.2 \%$ of the ever smokers (91) reported to have smoked a whole cigarette. The median (IQR) age at which the smokers first smoked a whole cigarette was 13.0 years \pm (3.0).

The prevalence of current smoker among the ever smokers was $28.5 \%$ indicating that they have smoked in the last 30 days preceding the survey. Two $(0.2 \%)$ of the current smokers indicated that they smoke at least 1 puff per day in the past 30 days. Twenty six respondents of the ever smokers indicated to be current smokers where $22(20 \%)$ smoked in the past 1-2 days, 3 (2.7\%) smoked in the last 3-5 days preceding the survey and $1(0.9 \%)$ smoked in 6-9 days before the survey.

Fourteen $(53.8 \%)$ of the current smokers reported that they smoke less than 1 cigarette in a day, $6(23.1 \%)$ reported that they smoke 1 stick per day, $6(23.1 \%)$ also reported to smoke between 2-5 cigarettes a day. Among the current smokers 7 (26.9\%) reported to have smoked earlier in the day, $10(38.5 \%)$ of the current smokers said they smoked sometimes in the last 7 days. 
Table II: Distribution of respondents by their smoking characteristics

\begin{tabular}{|c|c|c|c|}
\hline Smoking Characteristics (N=899) & $\mathbf{N}$ & $\%$ & Median (IQR) \\
\hline \multicolumn{4}{|l|}{ Ever Smoker $(n=899)$} \\
\hline $\begin{array}{l}\text { Yes } \\
\text { No }\end{array}$ & $\begin{array}{r}91 \\
808\end{array}$ & $\begin{array}{l}10.1 \\
89.9\end{array}$ & \\
\hline \multicolumn{4}{|l|}{ Age of Initiation $(n=91)$} \\
\hline$<7$ years & 5 & 5.5 & $12.00 \pm 4.00$ \\
\hline 7-9 years & 20 & 22.0 & \\
\hline $10-12$ years & 33 & 36.3 & \\
\hline $13-15$ years & 28 & 30.7 & \\
\hline 16 years and above & 5 & 5.5 & \\
\hline \multicolumn{4}{|l|}{ Smoked a whole cigarette $(n=91)$} \\
\hline Yes & 22 & 24.2 & \\
\hline No & 69 & 75.8 & \\
\hline Age started smoking a whole cigarette $(n=22)$ & & & $13.00 \pm 3.00$ \\
\hline $11-12$ years & 8 & 36.4 & \\
\hline 13-14 years & 7 & 31.8 & \\
\hline$>14$ years & 7 & 31.8 & \\
\hline \multicolumn{4}{|l|}{ Current smoker (n=91) } \\
\hline $\begin{array}{l}\text { Yes } \\
\text { No }\end{array}$ & $\begin{array}{l}26 \\
65\end{array}$ & $\begin{array}{c}28.5 \\
71.4\end{array}$ & \\
\hline \multicolumn{4}{|l|}{ Number of days of smoked in last 30 days $(n=91)$} \\
\hline $1-2$ & 22 & 20.0 & \\
\hline $3-5$ & 3 & 2.7 & \\
\hline $6-9$ & 1 & 0.9 & \\
\hline \multicolumn{4}{|l|}{$\begin{array}{l}\text { Number of cigarette sticks smoked in } 30 \text { days, } \\
(n=26)\end{array}$} \\
\hline$<1$ cigarette per day & 14 & 53.8 & \\
\hline 1 stick per day & 6 & 23.1 & \\
\hline 2 - 5 sticks per day & 6 & 23.1 & \\
\hline
\end{tabular}

\section{Association between Socio-demographic factor and Smoking}

Table III shows the association between sociodemographic characteristics and smoking. The results indicated that there was significant association between smoking and gender $(p=0.001)$. Smoking was found to be significantly higher in males (18.6\%) when compared to females (3.9\%). The findings also demonstrated that there was significant association between form (class) and smoking (x2 = 19.5; $\mathrm{df}=2$,

$p=0.001)$. Pairwise comparison indicated that the prevalence of smoking was highest among Form 4 students (16.3\%), followed by Form 2 (11.6\%) and lowest among Form 1 (5.1\%). Smoking prevalence was significantly higher among Form 4 student $(p=0.001)$ as compared to form 1 and also significantly higher in Form 2(11.6\%) than in Form 1(5.1\%) $(p=0.002)$. 
Table III: Association between socio-demographic factors, self-esteem and smoking

\begin{tabular}{|c|c|c|c|c|c|c|c|}
\hline \multirow[t]{2}{*}{$\begin{array}{l}\text { Socio-demographic } \\
\text { Factors }\end{array}$} & \multirow{2}{*}{$\begin{array}{l}\text { Eve } \\
\text { Yes } \\
n\end{array}$} & Sm & No & & \multirow[t]{2}{*}{$x^{2}$} & \multirow[t]{2}{*}{ Df } & \multirow[t]{2}{*}{$P$ Value } \\
\hline & & $\%$ & $\mathbf{N}$ & $\%$ & & & \\
\hline \multicolumn{8}{|l|}{ Age (years) } \\
\hline $12-13$ & 18 & 5.1 & 338 & 94.9 & 19.61 & 2 & $0.001^{*}$ \\
\hline $14-15$ & 39 & 11.7 & 295 & 88.3 & & & \\
\hline $16-17$ & 34 & 16.3 & 175 & 83.7 & & & \\
\hline \multicolumn{8}{|l|}{ Gender } \\
\hline Male & 71 & 18.6 & 310 & 81.4 & 52.67 & 1 & $0.001^{*}$ \\
\hline Females & 20 & 3.9 & 498 & 96.1 & & & \\
\hline \multicolumn{8}{|l|}{ Form (Class) } \\
\hline Form 1 & 18 & 5.1 & 337 & 94.9 & 19.49 & 2 & $0.001^{*}$ \\
\hline Form 2 & 39 & 11.6 & 296 & 88.4 & & & \\
\hline $\begin{array}{l}\text { Form } 3 \\
\text { Ethnicity }\end{array}$ & 34 & 16.3 & 175 & 83.7 & & & \\
\hline Malay & 91 & 10.2 & 802 & 89.8 & - & - & $0.526^{\mathrm{b}}$ \\
\hline $\begin{array}{l}\text { Others } \\
\text { Primary Education }\end{array}$ & 0 & - & 6 & 100.0 & & & \\
\hline Government & 52 & 11.3 & 410 & 88.7 & 14.22 & 5 & $0.014^{*}$ \\
\hline Private religious & 12 & 10.6 & 101 & 89.4 & & & \\
\hline State religion & 22 & 7.7 & 263 & 92.3 & & & \\
\hline $\begin{array}{l}\text { Others } \\
\text { Level of self esteem }\end{array}$ & 5 & 14.7 & 34 & 85.3 & & & \\
\hline Normal & 69 & 75.8 & 675 & 83.5 & 16.58 & 2 & $0.001^{*}$ \\
\hline Low & 20 & 22.0 & 74 & 9.2 & & & \\
\hline High & 2 & 2.2 & 59 & 7.3 & & & \\
\hline
\end{tabular}

Note: ${ }^{*} p$ value significant at less than $0.05,(b)=p$ value for fisher's Exact test

There was also significant association between age and smoking $(p=0.001)$. Pairwise comparison revealed highest prevalence among the oldest respondents (16-17 years). Smoking prevalence was significantly higher among 16-17 year old respondents $(16.3 \%) \quad(p=0.001)$ as compared to respondents of ages 12-13 years and also significantly $(p=0.002)$ higher in ages $14-15$ years $(11.7 \%)$ than in Form 1 (5.1\%). Among $12-13$ years olds it was $5.1 \%, 11.7 \%$ among $14-15$ years old and $16.3 \%$ among $16-17$ year old respondents.

However there was no significant association between prevalence of smoking and ethnicity level $(p=1.00)$. All smokers were found to be Malays. There was also significant association between the primary school attended and smoking $\left(x^{2}=14.22\right.$; $d f=5 ; p=0.014)$. Pairwise comparison indicated that prevalence was relatively highest among respondents who attended government primary school [52 out of $462(11.3 \%)$ ] followed by private religious school (10.6\%) and least among those that attend state religion primary school (7.7\%) $(p=0.003)$.

\section{Association between Self-esteem and Smoking}

Table III also shows the relationship between self- esteem and smoking $\left(x^{2}=16.58 ; \mathrm{df}=2 ; p=0.001\right)$. Statistical analysis showed that $22 \%$ of the smokers have low self-esteem (score $<15$ ) while only $2.2 \%$ of the ever smokers have high self- esteem. However a higher $(91 \%)$ number of the non-smokers have normal self-esteem.

\section{Simple Logistic Regression Analysis}

Table IV shows the results of the simple logistic regression. The results of the study shows that the odds of smoking is 5.7 times higher OR= 5.7; $95 \%$ $\mathrm{Cl}(3.40,9.55)$ in males when compared to females. The odds of smoking among ever smoker of age group 14-15 was 2.5 times higher $\mathrm{OR}=2.48 ; 95 \% \mathrm{Cl}$ $(1.39,4.43)$ but much higher (3.7 times) $95 \% \mathrm{Cl}$ $(2.00,6.65)$ in $16-17$ years old than those in the group 12-13 years old. The odds of smoking was found to be 2.5 times higher among form two students when compared to the form 1 students $\mathrm{OR}=2.47 ; 95 \% \mathrm{Cl}(1.38,4.41)$ and 3.6 times higher when compared to the form four students $O R=3.6$; $95 \% \mathrm{Cl}(1.99,6.63)$. The result of the study also shows the influence of parental background. The odds of smoking was also eight times higher (OR=. 7.97, 95\% Cl: $1.791,35.49$ ) in smokers who had low self- esteem when compared to those with high self- 
Table IV: Logistic regression showing significant predictors of smoking

\begin{tabular}{lllllll} 
Variables & COR & $95 \% \mathrm{Cl}$ & P value & AOR & $95 \% \mathrm{Cl}$ & $P$ Value \\
\hline $\begin{array}{l}\text { Gender } \\
\text { Females }\end{array}$ & 1 & & & & & \\
$\quad \begin{array}{l}\text { Males } \\
\text { Age (Years) }\end{array}$ & 5.70 & $3.40-9.55$ & $0.001^{*}$ & 5.54 & $3.12-9.84$ & $0.001^{*}$ \\
$\quad 12-13$ & 1 & & & & & \\
$14-15$ & 2.48 & $1.39-4.43$ & $0.002^{*}$ & 2.82 & $1.46-5.47$ & $0.002^{*}$ \\
$16-17$ & 3.65 & $2.00-6.65$ & $0.001^{*}$ & 3.63 & $1.79-7.34$ & $0.001^{*}$ \\
Form (Class) & & & & & & \\
$\quad$ Form 1 & 1 & & & & & \\
Form 2 & 2.47 & $1.38-4.40$ & $0.002^{*}$ & - & - & - \\
$\quad$ Form 4 & 3.64 & $1.99-6.63$ & $0.001^{*}$ & - & - & \\
Self esteem & & & & & & \\
$\quad$ High & 1 & & & & & \\
$\quad$ Normal & 3.02 & $0.721-12.61$ & 0.131 & 3.361 & $0.72-15.80$ & 0.13 \\
Low & 7.97 & $1.791-35.49$ & $0.006^{*}$ & 6.240 & $1.21-32.31$ & $0.03^{*}$ \\
\hline
\end{tabular}

Note: ${ }^{*} p$ value significant at less than 0.05 , COR-Crude odds ratio, AOR-Adjusted odds ratio

\begin{abstract}
Multivariate Logistic Regression
All variables were included in the preliminary model and were significantly associated with smoking in bivariate analysis $(p<0.05)$ and on the basis of their $p$ value greater than 0.05 but less than 0.25 (Hosmeret al., 2013) were analyzed using multivariate regression. The reference groups were: female, age $12-13$, form 1 , both parents having degree and having high self- esteem. Variables were analysed using both 'Forward-LR' and Enter' methods. After potential cofounders were controlled in the model, the factors that significantly predict smoking were gender, class and self-esteem.
\end{abstract}

Variables were then analysed using the 'enter' method. There was no multicollinearity; and there was no significant interaction between the different variables. The model tested to be worthwhile and fits the sample as $p=0.432$ for Hosmer-Lemeshow.

Table IV also presents the results of multivariate logistic regression for predicting smoking. The results indicated that males were 5.5 times more likely to smoke when compared to females. The risk of smoking was also found to be 2.8 times higher among 14-15 year olds but higher (3.6 times) among 16-17 year old students when compared with 12-13 year olds. The state of the mental health was also positively associated with smoking among respondents. The result of this study showed that the odds of smoking is 6.2 times higher in those who have low self-esteem when compared to those who have high self-esteem.

\section{DISCUSSION}

Prevalence of Smoking among Respondents

Smoking in this study is referred to respondents who have ever tried smoking cigarette, even a puff. In the present study, the prevalence of ever smoking among the students was found to be $10.1 \%$. This result is relatively lower than that reported in other government schools among adolescents but with little difference when compared to Reda et al, $(2012)^{13}$ which reported a smoking prevalence of 12.2\% among ever smoking adolescents in Ethopia, Africa. ${ }^{13}$ Also, this result is slightly higher than the Malaysia national prevalence $9.1 \%$ (YBRFSS, 2011) ${ }^{14}$ suggesting that the habit is not evenly distributed among the states. ${ }^{14}$ However having this proportion of ever smokers is disturbing in a religious school present in a community that has a standing 'fatwa' in which smoking is prohibited.

In the current study the prevalence of current smoking is $28.5 \%$. Lim et al.in $2010^{15}$ reported the prevalence of current smokers to be $35.5 \%$ while YBRFSS (2011) indicated a national prevalence of $8.7 \%$ among current smokers. However Sirirassamee et al., $(2011)^{16}$ reported a lower prevalence of current smokers at $5 \%$ and $8.6 \%$ ever smokers among adolescents in Thailand revealing a slight increase among school children in Malaysia of the same age group.

\section{Age of Initiation}

In the present study, the mean \pm SD age of initiation was $11.14 \pm 2.8$ years $(95 \% \mathrm{Cl} 10.96,11.32)$ while the median \pm IQR is $12.0(4.0)$ years indicating that most (69.8\%) of the ever smokers tried even before secondary schoo. In a similar study by Khairani et 
al., $(2007)^{17}$ it was reported that most of the ever smokers started between 13 to 15 years old $(66 \%)$ while only $21 \%$ of them began smoking during primary school $\left(<12\right.$ years old) ${ }^{17}$ However another study in Malaysia indicated that the median age of smoking initiation was lower among males when compared to female smokers (14 years old as against 15 years old). ${ }^{15}$

The results of this study shows a very close resemblance to the findings of Lim et al., $(2006)^{18}$ in a study in Kota Tinggi. ${ }^{18}$ It indicated that students started smoking as early as the age of 4 years old and begin to peak at upper primary level. The mean age of smoking initiation was 11.28 years $(95 \% \mathrm{Cl} 11.12$ to 11.45) while Juslina et al., $2011^{19}$ in a study in Sarawak reported the age of smoking initiation to be $12.8 \pm 1.9$ years. ${ }^{19}$ Lee et al., $(2005)^{8}$ in a study among Malaysian adolescents also reported $37.8 \%$ of the respondents started smoking at 13 to 14 years of age. ${ }^{8}$

From the above, it can be inferred that the upper primary years is an important stage in child development and socialization. The present study has revealed and supported results of previous studies that most of the ever smokers had their first puff just before secondary school.

\section{Socio-demographic Factors and Smoking}

In this study, the prevalence of smoking was higher among males $18.6 \%$ and only $3.9 \%$ among females which is similar to what was reported in other studies. Though relatively lower when compared to prevalence from other secondary schools in Malaysia. ${ }^{17,18}$ A possible reason could be due to religious reasons. However, Lee et al., (2005) $)^{8}$ reported a prevalence among the male students (26.6\%) and 3.1\% among female adolescents in Negeri Sembilan which is lower when compared to the present study. ${ }^{8}$

Gender was also positively associated in the bi-variate and multi-variate analysis. Males were between 3.1 times to 9.8 times more likely to smoke than female which is also in agreement with results from other findings. This result was found to be in agreement with other studies around the world and Malaysia inclusive. Lim et al., $(2006)^{16}$ revealed that boys are between 11.77 times to 59.98 times more likely to smoke than girls. This finding was also supported by Rachiotis et al., $2008^{20}$ in a study among Greek adolescents and among adolescents in Africa ${ }^{21}$ probably confirming the high prevalence around the world. $^{20,21}$

However in some studies in Zambia, ${ }^{22}$ Delhi and Goa (India) ${ }^{23}$ and the Czech Republic, ${ }^{23}$ no gender differences was observed between male and female gender. The high number of smokers among males could be because females are more socially restricted than their male counter parts. Another possible reason could be as a result of familial characteristics including care and family related activities which tend to give female children more responsibility.

Also students in older classes was found to be statistically significant with smoking. The proportion of smokers was highest among students in Form 4. The prevalence was highest among the 16-17 years age group, those in this age group are 3.7 times more likely to smoke than those in the lower age group (12-13) which could be as a result of the relative freedom or better chances of juvenile behaviours associated with older adolescents and older class. This is in agreement with the finding of Khairani et al., (2007) ${ }^{17}$ in another study among Malaysian adolescents. ${ }^{17}$

This present study did not show any significant difference between ethnicity and smoking but this could be because most of the respondents $(99 \%)$ are of the same ethnic group (Malay). The finding of this study is also consistent with the finding of Naing et al., $(2004)^{24}$ which reported no association between ethnicity and smoking. ${ }^{24}$ However Jeganathan, Hairi, Al Sadat and Karuthan $(2013)^{25}$ in a study among secondary school students in Perak reported a significant association between ethnicity and smoking. ${ }^{25}$

\section{Self-esteem and Smoking}

Self-esteem has been found to be a major reason for smoking initiation besides other factors. Self-esteem being a feeling of pride and self-value in one self. The study showed a significant difference between smoking and self-esteem. The result of the study found that respondents who smoke are six times more likely to have low self-esteem than those who do not smoke which was also supported by (Antti, Kentala, and Kari, 2015) ${ }^{26 .}$ The report stated that those respondents who had weaker self-esteem in adolescence had increased risk turning into regular smokers (adjusted OR 1.8, 95\% $\mathrm{Cl} 1.1-3.0){ }^{26}$

Bricker et al. (2009) in a study among adolescents indicated that there is a $22-27 \%$ odd between psychological factors and the probability that an adolescent would try smoking. ${ }^{27}$ Carters and Byrne $(2013)^{28}$ explained self-esteem in area-specific terms. The study reported that self-esteem in the areas of school subjects and parental relations were related to smoking indicating that adolescents with low self-esteem in these areas were more likely to smoke than those with high self-esteem. ${ }^{28}$ The reason why self- esteem tends to lead to higher rate of smoking is not immediately clear. However, a possible explanation is because self-esteem interferes in some way with the development of adaptive coping skills.

The majority of the respondents indicated a normal self-esteem. However studies have indicated that the positive association between smoking and level 
of self-esteem can be dependent on the age-group of the respondents. Previous reports which involve a year-on-year analysis of adolescents smoking behaviour reported a positive association between self-esteem and smoking in only certain age-group. ${ }^{29}$ The study indicated that at around age $12-14$ years, adolescents with low self-esteem take up smoking in increasing numbers than any other age-group and was reported to still smoke in subsequent years. ${ }^{27}$ This suggests that having a low self-esteem at a young age is an important risk factor towards smoking and that taking up smoking at a young age may also result in addiction. It is however unclear if low self-esteem results in smoking or vice versa.

However Yorulmaz, Aktürk, Dagdeviren and Dalkilic (2002) reported that there is no significant association between self-esteem and smoking. ${ }^{30}$ This was also supported by Mullan \& Nic Gabhainn (2002) in a study among Irish high school students aged 1017 years which indicated no significant difference in self-esteem score between smokers and nonsmokers ${ }^{31}$ It should however be noted that the insignificant association observed could be as a result of other independent variables under study, hence suppressing the effect of self- esteem.

Further studies are therefore required to establish the relationship between smoking and later youth stage self-esteem, as there could be a peer factor confounding with the early youths' self-esteem. Seo and Huang (2012) supported this notion by indicating that adolescents who are identified or see themselves as isolates are more likely to smoke and engage in risk-taking behaviours than others in his/her peer group. ${ }^{32}$

\section{CONCLUSION}

The high prevalence of smoking among respondents has been able to outline and establish the role of socio-demographic factors and self-esteem in initiation of smoking. The study has established the importance of proper monitoring of children and adolescents since most of the reported smokers initiated the act even before secondary school. This study re-affirms the notion that the pre-high school period as an important period for initiation of smoking during adolescents transition to adulthood. The result of the study also highlights the importance of self -esteem in the lives of teenagers. A high feeling of self-worth and self-esteem is reportedly protective against initiation of smoking.

Further cohort studies should also be conducted in these schools to confirm likely causes of this menace.

\section{Acknowledgement}

Heartfelt appreciation to all the Principals, Coordinators and students of the schools in which this study was conducted, without which this research would have been impossible. My gratitude

\section{REFERENCES}

1. Peto R, Lopez AD, Boreham J, et al. Mortality from smoking worldwide. British Medical Bulletin 1996; 52:12-21.

2. World Health Organization (WHO). Tobacco free initiative (TFI): Why is tobacco a public health priority? 2013. Retrieved from: http:// www.who.int/tobacco/health_priority/ en webcite

3. Crofton J. and Simpson D. Tobacco: A Global Threat Curbing the Epidemic. Government and the Economics of Tobacco Control; 2002. Available from: World Bank Tobacco Report 1999.

4. Gilliland FD, Islam T, Berhane K, et al. Regular smoking and asthma incidence in adolescents. Am J Respir Cirt Care Med 2006; 174:1094-100.

5. Ministry of Health Malaysia. Global Adult Tobacco Survey 1 Report (GATS) 2011. Malaysia 2012: Institute of Public Health.

6. Pierce JP, Gilpin E. How long will today's adolescent smoker be addicted to cigarettes? American Journal of Public Health 1996; 86:253-6.

7. Rashid AK, Azizah AM. Smoking Habits among Medical Students in a Private University. Malaysian Journal of Public Health Medicine 2011; 11: 70-7.

8. Lee LK, Paul, CY, Kam CW, Jagmohni K. Prevalence of smoking and factors influencing cigarette smoking among secondary school students in Negeri Sembilan, Malaysia. Asia Pacific Journal of Public Health 2005; 17:130-6.

9. McGee R, Williams S. Predictors of persistent smoking and quitting among women smokers. Addictive Behaviour 2006; 31:1711-5.

10. Byrne DG, Mazanov J. Self-esteem, stress and cigarette smoking in adolescents. Stress and Health 2001; 17:105-10.

11. Rosenberg M. Society and the adolescent selfimage. Princeton, NJ: Princeton University Press (1965)

12. Mohd. Jamil, B. Validity and Reliability study of Rosenberg Self- esteem scale in Seremban School Children. Journal of psychiatry 2006; 15:35-39.

13. Reda AA, Asmamaw M, Berhanu Y, Sibhatu B. Determinants of cigarette smoking among school adolescents in eastern Ethiopia: a cross-sectional study. Harm Reduction Journal 2012; 9(39).

14. Institute for Health Behavioural Research, Ministry of Health, Malaysia . Youth Behaviour Risk Factor Surveillance (YBRFSS). Statistical Report-Baseline results, 2011.

15. Lim SG, Chung WJ, Kim HJ, Lee SM. The influence of housing tenure and marital status on smoking in South Korea. Health Policy 2010; 94:101-10.

16. Sirirassamee T, Sirirassamee B, Borland R, Omar $M$, Driezen P. Smoking behavior among adolescents in Thailand and Malaysia. Southeast Asian Journal of Tropical Medicine \& Public Health 2011; 42:218-24.

17. Khairani O, Norazua R, Zaiton A. Prevalence and Reasons for Smoking among Upper Secondary 
School boys in Hulu Langat, Malaysia. Medicine \& Health 2007; 2:80-5.

18. Lim KH, Amal NM, Hanjeet K, et al. Prevalence and factors related to smoking among secondary school students in Kota Tinggi District, Johor, Malaysia. Tropical Biomedicine 2006; 23:75-84.

19. Juslina O, Leelavathi $M$, Khairani O, Iryani T. Prevalence of smoking among secondary school students in Sarawak. Malaysian Family Physician 2011; 6, (2\&3) ISSN: 1985-207X (print), 19852274.

20. Rachiotis G, Muula AS, Rudatsikira E. Factors associated with adolescent cigarette smoking in Greece: Results from a cross sectional study (GYTS Study). BioMed Central Public Health 2008; 8: 313.

21. Rudatsikira E, Dondog J, Siziya S. and Muula A.S. Prevalence and determinants of adolescent cigarette smoking in Mongolia. Singapore Medical Journal 2008; 49:57-62.

22. Siziya S, Rudatsikira E, Muula AS, Ntata PR. Predictors of cigarette smoking among adolescents in rural Zambia: results from a cross sectional study from Chongwe district. Rural and Remote Health 2007; 7:728-32.

23. Global Youth Tobacco Survey Collaborating Group (2003). Differences in worldwide tobacco use by gender: findings from the Global Youth Tobacco Survey. Journal of School Health 2003; 73: 207-15.

24. Naing NN, Zulkilfi A, Razlan M, et al. Factors related to smoking habits of male adolescents. Tobacco Induced Diseases 2004; 2:133-40.

25. Jeganathan, PD, Hairi NN, Nabilla Al Sadat N, Karuthan C. Smoking stage relations to peer, school and parental factors among secondary school students in Kinta, Perak. Asian Pacific Journal of Cancer Prevention 2013; 14:3483-9.

26. Antti JS, Jukka K, Kari JM. Weaker Self-Esteem in Adolescence Predicts Smoking. BioMed Research International 2015, Article ID 687541, in press

27. Bricker JB, Rajan KB, Zalewski $M$, et al. Psychological and social risk factors in adolescent smoking transitions: a populationbased longitudinal study. Health Psychology 2009, 28:439-47.

28. Carters MA, Byrne DG. The role of stress and area-specific self-esteem in adolescent smoking. Australian Journal of Psychology 2013; 65:180-7.

29.Glendinning A. Self-esteem and smoking in youth--muddying the waters? Journal of Adolescence 2002; 25: 415-25.

30. Yorulmaz F, Aktürk Z, Dagdeviren N, Dalkilic A. Smoking among adolescents: relation to school success, socioeconomic status, nutrition, and self-esteem. Swiss Medical Weekly 2002; 132: 449-54.

31. Mullan E, NicGabhainn S. Self-esteem and health-risk behaviours: Is there a link? The Irish
Journal of Psychology 2002; 23:27-36.

32. Seo DC, Huang Y. Systematic review of social network analysis in adolescent cigarette smoking behavior. Journal of School Health 2012; 82:21-7. 